\title{
Оценка влияния инвестиционного климата региона на эффективность налоговых льгот
}

\section{Евгения Попова}

Читинский институт (филиал) Байкальского государственного университета, Чита, Россия

\author{
Информация о статье \\ Поступила в редакцию: \\ 21.08.2018 \\ Принята \\ к опубликованию: \\ 23.05.2019 \\ УДК 336.5 \\ JEL H21
}

\section{Ключевые слова:}

инвестиционный процесс, инвестиционный климат, налоговые льготы, экономическая эффективность, налоговая нагрузка, предельная эффективная ставка, комплексный анализ

\section{Keywords:}

investment process, investment climate, tax benefits, economic effectiveness, tax burden, marginal effective rate, comprehensive analysis

\begin{abstract}
Аннотация
Исследование показывает, что состояние сочиальноэкономической и институциональной среды оказывает влияние на эффективность инвестиционных налоговых льгот, устанавливаемых для российских субъектов. Обосновывается иелесообразность вычисления индикаторов инвестиционного климата и проведения сравнительного анализа с другими регионами на этапе введения налоговых льгот. В статье приведен пример реализачии данного инструментария. Его применение является неотъемлемым элементом комплексного анализа, особенно в том случае, если прогноз показателей эффективности невозможен в силу отсутствия потенциальных инвесторов-бенефициаров налоговых льгот.
\end{abstract}

Assessment of the Region Investment Climate Impact on the Tax Benefits Effectiveness

Evgeniya Popova

\section{Abstract}

The investigation conducted showed that the socio-economic and institutional environment had an impact on the effectiveness of the investment allowance established in the Russian regions. The expediency of calculating the investment climate indicators and benchmarking with other regions at the stage of the tax benefits adoption was substantiated. The article describes an example of this instrument implementation. Its application is an essential element of the complex analysis, especially when the performance measurements assumption is improbable due to the lack of potential investors-beneficiaries of tax benefits. The results of the ANOVA allow us to conclude on the practicability of calculating the investment climate indicators at the stage of the tax benefits adoption. Scientific novelty and practical significance of the proposed instrument is in making the analysis more complicated at the stage of the benefits adoption. But, according to the facts on the ground, the regions predict the key performance indicators only if the benefits are provided to a specific investment project. Thus, in the market economy, where regions act as quasi-corporations, competing for attracting the investment resources, it is reasonable to carry out a comparative analysis of

DOI: https://dx.doi.org/10.24866/2311-2271/2019-4/124-135 
the investment climate at the stage of the tax benefits adoption, since, as it is shown by the investigation, socio-economic and institutional environment has an impact on the effectiveness of the investment allowance.

\section{Введение}

Проблема налогового регулирования инвестиций отличается своей многогранностью и состоит в следующих принципиальных вопросах: степень влияния, оказываемого налогами на объемы и отраслевую структуру капиталовложений, и целесообразность использования налоговых мер при проведении государственной инвестиционной политики. Следует подчеркнуть, что разрешение проблемы налогового регулирования инвестиций напрямую связано с вопросом о функциональной природе налога. Экономисты (Дордевик, Бернарди, Чандлер, Чигбу, И.В. Горский, И.А. Макарова) продолжают рассматривать налоги, в первую очередь, как инструмент генерирования государственных доходов, и не выделяют функции регулирования $[1,2]$. Ключевой вопрос использования налоговых льгот - это оценка их эффективности. Именно сложность проведения объективной оценки и отсутствие единых подходов выступают в качестве главного аргумента сторонников той точки зрения, что налоги имеют весьма ограниченный потенциал в стимулировании инвестиционной деятельности. Результаты крупномасштабных международных исследований свидетельствуют о том, что величина налогового бремени далеко не самый важный фактор в принятии инвестиционных решений. Так Организация Объединённых Наций по промышленному развитию проводила опрос, который охватывал около 7000 фирм в 19 странах мира. Результаты показали, что из 12 факторов, оказывающих влияние на инвестиционные решения, налоговые льготы находятся на 11 месте [3].

С другой стороны, ряд исследований доказывают, что эффективность налогового регулирования инвестиций в большинстве своем определяется не фискальными факторами (конструкцией налога), а существующими экономическими, социальными и правовыми условиями, другими словами, состоянием социально-экономической и институциональной среды [4]. Состояние социально-экономической и институциональной среды можно количественно оценить, исчислив такие интегральные индикаторы, как инвестиционный потенциал, инвестиционный риск и инвестиционная активность. Данные индикаторы определяют инвестиционную конкурентоспособность или инвестиционный климат региона. В статье предложена методика оценки инвестиционного климата региона, которая была разработана с учетом недостатков существующих подходов и методик.

Цель исследования заключается в оценке влияния социальноэкономической и институциональной среды реализации регионального инвестиционного процесса на эффективность инвестиционных налоговых льгот, установленных в соответствии с законодательством субъекта Российской Федерации. Инициируемое нами исследование, которое проводилось на основе эконометрического инструментария и фактических статистических данных, позволит дать количественную оценку чувствительности эффективности налоговых льгот, применяемых в российских регионах, к состоянию инвестиционного климата. Практическая значимость полученных результатов состоит в обосновании необходимости анализа состояния инвестиционного климата региона на этапе введения налоговых льгот. 


\section{Методология проведенного исследования}

Для проведения дисперсионного анализа важно уточнить, что в качестве фактора (группировочного признака) будет выступать индикатор, характеризующий состояние инвестиционного климата региона, а результативным признаком - показатели эффективности налоговых льгот. Первым шагом найдем показатели эффективности инвестиционных налоговых льгот. Далее рассчитаем интегральные индикаторы инвестиционного климата и сформируем соответствующие группы. Наконец, используя пакет анализа в программе MS Excel, установим значимость влияния группировочного признака.

Отсутствие унифицированной методики оценки эффективности региональных налоговых льгот существенно затрудняет проведение дисперсионного анализа, поскольку необходимо соблюдение условия сопоставимости исходных данных, другими словами, показатели эффективности должны быть получены на основе единого алгоритма. Однако изучение методик, применяемых в российских регионах, позволило сделать вывод о том, что наибольшей универсальностью отличается порядок расчета критерия бюджетной и экономической эффективности налоговых льгот $[5,6,7,8]$. Выбор критерия экономической эффективности для проведения дисперсионного анализа продиктован тем, что он охватывает больший набор показателей и, соответственно, позволяет повысить его качество. Кроме того, основной канал воздействия налогов на инвестиционные решения - это экономические показатели, характеризующие результаты реализации проекта. Так экономическая эффективность представляет собой оценку динамики производственных и финансово-экономических показателей хозяйственной деятельности налогоплательщика. Можно выделить несколько вариантов расчета данного критерия.

1. Определяется отношение количества показателей, по которым произошел рост (уровень остался прежним) по сравнению с предыдущим годом, к количеству показателей, по которым произошло снижение. Льгота признается эффективной, если значение коэффициента больше или равно единице (Новосибирская область, Амурская область, Хабаровский край).

2. Устанавливается минимальное число показателей, по которым должна быть обеспечена положительная динамика для того, чтобы льгота была признана эффективной. Например, в Омской области не менее 4-х показателей, в Кировской - не менее 3-х.

3. По формуле средней арифметической (средневзвешенной) находится среднее значение темпов роста показателей финансово-экономической деятельности предприятия (Приморский край, Ставропольский край). Сводный коэффициент экономической эффективности должен быть равен или больше единицы.

4. Применение балльной оценки. Вначале рассчитываются темпы роста по каждому показателю с корректировкой на индекс-дефлятор. Если наблюдается положительная динамика, показателю присваивается 1 балл, если отрицательная - 0 баллов. Затем по формуле средней арифметической исчисляется сводный коэффициент экономической эффективности. Например, в Ленинградской области значение должно быть больше 0,8 .

Исходя из вышеизложенного, для дисперсионного анализа будем использовать коэффициенты экономической эффективности налоговых льгот по налогу на прибыль организаций. В разных регионах предусмотрен разный набор финансово-экономических показателей, однако аналитические записки и отче- 
ты профильных министерств и ведомств содержат подробную информацию о динамике основных показателей предприятий, получающих налоговые льготы. В связи с чем, был определен общий для всех регионов перечень показателей, на основе которых осуществлялся дополнительный расчет коэффициентов экономической эффективности по единому алгоритму (табл. 1). Таким образом была решена проблема сопоставимости исходных данных.

Таблица 1

Группировка регионов по индикатору инвестиционного климата

\begin{tabular}{|c|c|c|}
\hline $\begin{array}{c}\text { Группы регионов по } \\
\text { индикатору инвестици- } \\
\text { онного климата }\end{array}$ & Субъект России & $\begin{array}{c}\text { Коэффициенты экономической эффек- } \\
\text { тивности инвестиционных налоговых } \\
\text { льгот по налогу на прибыль }\end{array}$ \\
\hline \multirow{5}{*}{$\begin{array}{c}\text { I группа } \\
(0,6149-0,7214)\end{array}$} & Кемеровская область & 1,46 \\
\hline & Астраханская область & 0,87 \\
\hline & Волгоградская область & 0,71 \\
\hline & Республика Бурятия & 1,17 \\
\hline & Кировская область & 1,02 \\
\hline \multirow{7}{*}{$\begin{array}{c}\text { II группа } \\
(0,7214-0,8279)\end{array}$} & Мурманская область & 1,13 \\
\hline & Новосибирская область & 1,11 \\
\hline & Омская область & 1,33 \\
\hline & Ставропольский край & 1,18 \\
\hline & Амурская область & 1,08 \\
\hline & Иркутская область & 1,25 \\
\hline & Приморский край & 1,31 \\
\hline \multirow{6}{*}{$\begin{array}{c}\text { III группа } \\
(0,8279-0,9344)\end{array}$} & Хабаровский край & 1,36 \\
\hline & Калужская область & 1,42 \\
\hline & Нижегородская область & 1,54 \\
\hline & Ленинградская область & 1,48 \\
\hline & Ростовская область & 1,34 \\
\hline & Краснодарский край & 1,38 \\
\hline \multirow{2}{*}{$\begin{array}{c}\text { IV группа } \\
(0,9344-1,0409)\end{array}$} & Липецкая область & 1,43 \\
\hline & Тюменская область & 1,56 \\
\hline
\end{tabular}

Источник: составлено автором

Наконец, определим алгоритм расчета коэффициентов экономической эффективности инвестиционных налоговых льгот. Предлагаем использовать формулу средневзвешенного значения. Веса показателей исчислим, применив метод простого ранжирования. Суть проста: пусть у нас $\mathrm{n}$ критериев, самому важному присваивают $\mathrm{n}$ очков, следующему по приоритетности $\mathrm{n}-1$ и т.д. Полученные оценки делятся на сумму $1+2+\ldots+n$. В итоге сумма весов будет равна 1 (формула 1).

$$
K_{e}=T_{q} \times 0,2+T_{c} \times 0,13+T_{r} \times 0,27+T_{p} \times 0,33+T_{j} \times 0,07,
$$

где $K_{e}$ - коэффициент экономической эффективности налоговых льгот;

$T_{q}$ - темп роста показателя «отгружено товаров собственного производства»;

$T_{c}$ - темп роста показателя «среднегодовая стоимость основных средств»;

$T_{r}$ - темп роста показателя «выручка»;

$T_{p}$ - темп роста показателя «прибыль до налогообложения»;

$T_{j}$ - темп роста показателя «среднесписочная численность работников».

Следующий шаг состоит в исчислении индикаторов, характеризующих инвестиционный климат в данных регионах. Одной из наиболее приемлемых методик по оценке состояния среды реализации инвестиционного процесса на региональном уровне является методика, основанная на временном подходе (расширенном рисковом), согласно которому инвестиционный климат пред- 
ставляет собой инвестиционную привлекательность в динамическом аспекте [9]. То есть для определения состояния инвестиционного климата необходимы данные о состоянии инвестиционной привлекательности региона за период не менее 5 лет. В основе предложенной нами методики лежат элементы индикативного анализа и подход, используемый рейтинговым агентством «Эксперт РА», в соответствии с которым инвестиционная привлекательность региона складывается из инвестиционного потенциала, включающего 8 частных потенциалов, и инвестиционного риска, состоящего из 4-х видов частных рисков. В свою очередь, каждый частный потенциал и каждый частный риск характеризуется совокупностью статистических показателей (табл. 2).

Для исчисления нормализованных значений отдельных показателей в качестве базы нами использовались максимальные значения конкретных показателей, зафиксированные среди всех регионов за каждый год исследования, что позволяет получить наиболее реалистичные оценки и отследить изменение инвестиционной привлекательности регионов в динамике.

Веса показателей, формирующих частный индикатор, определяли способом простого ранжирования: чем больше коэффициент корреляции исходного показателя и объемов инвестиций в основной капитал (не менее 0,3 ), тем больше значимость показателя. Веса же самих частных индикаторов, агрегируемых в интегральные индикаторы, исчисляли экспертным путем на основе упрощенного варианта метода анализа иерархий, изложенного в работах В.Д. Ногина $[10,11]$ Основным достоинством предложенного способа вычисления вектора приоритетов является высокая надежность экспертных оценок ввиду формирования совместной матрицы.

Проведение критического анализа существующих методик позволило выделить следующий недостаток: при оценке инвестиционного климата они не учитывают отраслевую структуру региональной экономики, которая, в свою очередь, оказывает дополнительное влияние на заинтересованность потенциальных инвесторов инвестировать в тот или иной регион $[12,13,14]$. Принимая во внимание такую негативную тенденцию как снижение удельного веса реальных инвестиций в обрабатывающих отраслях и общую ресурсоориентированную модель российской экономики, развитая обрабатывающая промышленность выступает конкурентным преимуществом региона. В связи с чем, предлагаем учесть отраслевую структуру экономики регионов как фактор инвестиционной привлекательности при расчете производственного потенциала и коэффициентов диверсификации сильных и слабых конкурентных позиций региона. Если доля добавленной стоимости, создаваемой в обрабатывающих производствах, выше среднего уровня, зафиксированного среди анализируемых регионов, на $20 \%$ и более, то это следует рассматривать как сильную конкурентную позицию, если меньше на $20 \%$ и более - как слабую конкурентную позицию.

Алгоритм исчисления интегральных показателей представлен ниже.

1. Сбор необходимой статистической информации по регионам $[15,16]$.

2. Расчет нормированных показателей по формуле:

$$
P=\frac{P_{\text {факm }}}{P_{\text {макс }}}
$$

где $P_{\text {факт }}$ - фактическое значение показателя по конкретному региону;

$P_{\text {макс }}$ максимальное значение показателя, зафиксированное по всем наблюдаемым регионам. 
Таблийа 2

Набор показателей, характеризующих частные индикаторы инвестиционного потенциала и инвестиционного риска

\begin{tabular}{|c|c|c|c|}
\hline $\begin{array}{l}\text { Интегральный } \\
\text { индикатор }\end{array}$ & $\begin{array}{c}\text { Частный } \\
\text { индикатор }\end{array}$ & \begin{tabular}{|c|} 
Весовой коэф- \\
фициент частно- \\
го индикатора
\end{tabular} & Показатель, ед. измерения \\
\hline \multirow{25}{*}{$\begin{array}{c}\text { Инвестицион- } \\
\text { ный потенци- } \\
\text { ал }\end{array}$} & \multirow{2}{*}{$\begin{array}{c}\text { Производ- } \\
\text { ственный } \\
\text { потенциал } \\
\end{array}$} & \multirow[b]{2}{*}{0,22} & ВРП на душу населения, руб. \\
\hline & & & $\begin{array}{l}\text { Удельный вес обрабатывающих производств в валовой добавленной стои- } \\
\text { мости, \% }\end{array}$ \\
\hline & \multirow{5}{*}{$\begin{array}{c}\text { Трудовой } \\
\text { потенциал }\end{array}$} & \multirow{5}{*}{0,19} & $\begin{array}{l}\text { Население в трудоспособном возрасте по отношению ко всему населению } \\
\text { региона, \% }\end{array}$ \\
\hline & & & Ожидаемая продолжительность жизни при рождении, лет \\
\hline & & & $\begin{array}{l}\text { Естественный прирост населения на } 1000 \text { человек, чел. (если наблюдается } \\
\text { естественная убыль, то показатель принимает нулевое значение) }\end{array}$ \\
\hline & & & $\begin{array}{l}\text { Численность студентов государственных и муниципальных профессио- } \\
\text { нальных образовательных организаций, обучающихся по программам } \\
\text { подготовки специалистов среднего звена на } 10000 \text { человек населения, чел. }\end{array}$ \\
\hline & & & $\begin{array}{l}\text { Численность студентов, обучающихся по программам бакалавриата, спе- } \\
\text { циалитета, магистратуры на } 10000 \text { человек населения, чел. }\end{array}$ \\
\hline & \multirow{4}{*}{$\begin{array}{c}\text { Потреби- } \\
\text { тельский } \\
\text { потенциал }\end{array}$} & \multirow{4}{*}{0,17} & Среднедушевые денежные доходы, руб. \\
\hline & & & Потребительские расходы в среднем на душу населения, руб. \\
\hline & & & Число собственных легковых автомобилей на 1000 человек населения, шт. \\
\hline & & & $\begin{array}{l}\text { Общая площадь жилых помещений, приходящаяся в среднем на одного } \\
\text { жителя, кв. м. }\end{array}$ \\
\hline & \multirow{2}{*}{$\begin{array}{c}\text { Инфра- } \\
\text { структур- } \\
\text { ный потен- } \\
\text { циал }\end{array}$} & \multirow{2}{*}{0,14} & $\begin{array}{l}\text { Плотность автомобильных дорог общего пользования с твердым покрыти- } \\
\text { ем, км путей на } 1000 \text { км² территории }^{2}\end{array}$ \\
\hline & & & $\begin{array}{l}\text { Наличие квартирных телефонных аппаратов } \\
\text { сети общего пользования на } 1000 \text { человек городского населения, шт. }\end{array}$ \\
\hline & \multirow{4}{*}{$\begin{array}{c}\text { Финансо- } \\
\text { вый потен- } \\
\text { циал }\end{array}$} & \multirow{4}{*}{0,11} & $\begin{array}{l}\text { Сальдированный финансовый результат деятельности организаций в } \\
\text { расчете на одну организацию, тыс. руб. (если отрицательное значение, то } \\
\text { показатель принимает нулевое значение) }\end{array}$ \\
\hline & & & $\begin{array}{l}\text { Вклады (депозиты) юридических и физических лиц в рублях, привлеченные } \\
\text { кредитными организациями в расчете на душу населения, млн. руб. }\end{array}$ \\
\hline & & & $\begin{array}{l}\text { Профицит консолидированного бюджета по отношению к ВРП, \% (если } \\
\text { дефицит, то показатель принимает нулевое значение) }\end{array}$ \\
\hline & & & Доля собственных доходов в доходной части регионального бюджета, \% \\
\hline & \multirow{2}{*}{$\begin{array}{c}\text { Институ- } \\
\text { циональный } \\
\text { потенциал }\end{array}$} & \multirow[b]{2}{*}{0,08} & Число малых предприятий по отношению к общему числу предприятий, \% \\
\hline & & & $\begin{array}{l}\text { Число индивидуальных предпринимателей по отношению к численности } \\
\text { населения, \% }\end{array}$ \\
\hline & \multirow{2}{*}{$\begin{array}{l}\text { Инноваци- } \\
\text { онный } \\
\text { потенциал }\end{array}$} & \multirow{2}{*}{0,06} & $\begin{array}{l}\text { Количество организаций, осуществляющих технологические, организаци- } \\
\text { онные, маркетинговые инновации в общем числе организаций, \% }\end{array}$ \\
\hline & & & $\begin{array}{l}\text { Объем инновационных товаров, работ, услуг в общем объеме товаров, } \\
\text { работ, услуг, \% }\end{array}$ \\
\hline & \multirow{4}{*}{$\begin{array}{l}\text { Природно- } \\
\text { ресурсный } \\
\text { потенциал }\end{array}$} & \multirow{4}{*}{0,03} & $\begin{array}{l}\text { Объем добычи топливно-энергетических полезных ископаемых в расчете } \\
\text { на одного жителя, тонн условного топлива }\end{array}$ \\
\hline & & & $\begin{array}{l}\text { Объем добычи минеральных полезных ископаемых в расчете на одного } \\
\text { жителя, тыс. руб. (в сопоставимых ценах) }\end{array}$ \\
\hline & & & Площадь сельскохозяйственных угодий в расчете на одного жителя, га \\
\hline & & & Общий запас древесины в расчете на одного жителя, тыс. м ${ }^{3}$ \\
\hline \multirow{12}{*}{$\begin{array}{l}\text { Инвестицион- } \\
\text { ный риск }\end{array}$} & \multirow{3}{*}{$\begin{array}{l}\text { Экономиче- } \\
\text { ский риск }\end{array}$} & \multirow{3}{*}{0,38} & Индекс потребительских цен, \% \\
\hline & & & Уровень безработицы, \% \\
\hline & & & Степень износа основных фондов, \% \\
\hline & \multirow{4}{*}{$\begin{array}{l}\text { Финансо- } \\
\text { вый риск }\end{array}$} & \multirow{4}{*}{0,32} & $\begin{array}{l}\text { Дефицит регионального бюджета по отношению к ВРП, \% (если профицит, } \\
\text { то показатель принимает нулевое значение) }\end{array}$ \\
\hline & & & $\begin{array}{l}\text { Задолженность по налогам, сборам и иным обязательным платежам в } \\
\text { бюджетную систему РФ на душу населения, тыс. руб. }\end{array}$ \\
\hline & & & $\begin{array}{l}\text { Государственный долг субъекта по отношению к налоговым и неналоговым } \\
\text { доходам бюджета, \% }\end{array}$ \\
\hline & & & Удельный вес убыточных организаций, \% \\
\hline & $\begin{array}{c}\text { Правовой } \\
\text { (законода- } \\
\text { тельный) } \\
\text { риск }\end{array}$ & 0,13 & $\begin{array}{l}\text { Экспертная оценка правового (законодательного) риска по } 10 \text { балльной } \\
\text { шкале с учетом качественных показателей }\end{array}$ \\
\hline & \multirow{4}{*}{$\begin{array}{l}\text { Социаль- } \\
\text { ный риск }\end{array}$} & \multirow{4}{*}{0,17} & $\begin{array}{l}\text { Удельный вес численности населения с денежными доходами ниже вели- } \\
\text { чины прожиточного минимума в общей численности населения субъекта, \% }\end{array}$ \\
\hline & & & Коэффициент Джини (в долях единицы) \\
\hline & & & $\begin{array}{l}\text { Коэффициент демографической нагрузки, на } 1000 \text { человек трудоспособного } \\
\text { возраста приходится лиц старше трудоспособного возраста }\end{array}$ \\
\hline & & & $\begin{array}{l}\text { Количество времени, не отработанного работниками, участвовавшими в } \\
\text { забастовках, тыс. человеко-дней }\end{array}$ \\
\hline
\end{tabular}

Источник: составлено автором 
3. Расчет частных потенциалов (рисков) по формуле:

$$
I=\sum_{i=1}^{n} P_{i} \times f_{i},
$$

где $I$ - частный потенциал (риск);

$P_{i}-$ i-ый нормированный показатель частного потенциала (риска);

$f_{i}$ - весовой коэффициент i-ого нормированного показателя;

$n$-количество показателей, составляющих частный потенциал (риск);

4. Расчет интегрального индикатора инвестиционного потенциала (инвестиционного риска) по формуле:

$$
P=\sum_{j=1}^{m} I_{j} \times w_{j}
$$

где $P$ - интегральный индикатор;

$I_{j}-$ j-ый частный потенциал (риск);

$w_{j}$ - весовой коэффициент ј-ого частного потенциала (риска);

$m$ - количество частных потенциалов (рисков), формирующих соответствующие интегральные индикаторы.

5. Вычисление коэффициентов диверсификации сильных (слабых) конкурентных позиций региона.

5.1. Найдем среднее значение каждого показателя для анализируемых регионов;

5.2. Стандартизируем значение показателя по конкретному региону через его отношение к среднему значению;

5.3. Если стандартизированное значение равно или больше 1,2, то это расценивается как сильная конкурентная позиция. Если стандартизированное значение равно или меньше 0,8 , то это расценивается как слабая конкурентная позиция.

5.4. Для каждого региона находим общее количество сильных (слабых) конкурентных позиций.

5.5. Вычисляем среднее количество сильных (слабых) конкурентных позиций по анализируемым регионам.

5.6. Находим коэффициенты диверсификации по следующим формулам:

$$
K_{s}=\frac{n_{s}}{n_{\text {savg }}}
$$

где $K_{s}$ - коэффициент диверсификации сильных конкурентных позиций;

$n_{s}$ - общее количество сильных конкурентных позиций региона;

$n_{\text {savg }}$ - среднее количество сильных конкурентных позиций по всем регионам.

$$
K_{w}=\frac{n_{w}}{n_{\text {wavg }}},
$$

где $K_{w}$ - коэффициент диверсификации слабых конкурентных позиций;

$n_{w}$ - общее количество слабых конкурентных позиций региона;

$n_{\text {wavg }}$ - среднее количество слабых конкурентных позиций по всем регионам.

6. Определение итоговой величины инвестиционной привлекательности региона по формуле:

$$
I A=P_{p}+\left(1-P_{r}\right)+K_{s}+\left(1-K_{w}\right)
$$

где $I A$ - инвестиционная привлекательность региона;

$P_{p}$ - интегральный индикатор инвестиционного потенциала;

$P_{r}-$ интегральный индикатор инвестиционного риска;

$K_{s}$ - коэффициент диверсификации сильных конкурентных позиций;

$K_{w}$ - коэффициент диверсификации слабых конкурентных позиций. 
Поскольку индикатор инвестиционного риска и коэффициент диверсификации слабых конкурентных позиций региона являются негативными величинами, при суммировании негативных и позитивных индикаторов необходимо негативную величину преобразовать в позитивную форму, для этого предлагаем к интегральному индикатору инвестиционного риска и коэффициенту диверсификации слабых конкурентных позиций прибавить 1. Это позволит сохранить вектор его воздействия на итоговый индикатор и межрегиональную дифференциацию.

7. Индикатор, характеризующий состояние инвестиционного климата в регионе, представляет собой среднее значение индикаторов инвестиционной привлекательности, рассчитанных за некоторый период.

Как уже отмечалось выше, для определения состояния инвестиционного климата в отдельных субъектах Российской Федерации необходимо рассчитать индикаторы инвестиционной привлекательности за некоторый период времени, а затем исчислить их среднее значение. В настоящем исследовании был охвачен временной период с 2010 по 2016 г. Объектами анализа выступили 20 российских регионов. Итоговые результаты проведенных расчетов представлены в табл. 3.

Таблица 3

Индикаторы, характеризующие состояние инвестиционного климата в российских регионах

\begin{tabular}{|l|c|}
\hline \multicolumn{1}{|c|}{ Регион } & \multicolumn{1}{|c|}{ Значение индикатора } \\
\hline Мурманская область & 0,761 \\
\hline Кемеровская область & 0,631 \\
\hline Новосибирская область & 0,750 \\
\hline Омская область & 0,753 \\
\hline Хабаровский край & 0,879 \\
\hline Калужская область & 0,862 \\
\hline Ставропольский край & 0,792 \\
\hline Астраханская область & 0,615 \\
\hline Амурская область & 0,726 \\
\hline Нижегородская область & 0,853 \\
\hline Ленинградская область & 0,901 \\
\hline Волгоградская область & 0,677 \\
\hline Ростовская область & 0,848 \\
\hline Липецкая область & 0,949 \\
\hline Тюменская область & 1,041 \\
\hline Иркутская область & 0,723 \\
\hline Республика Бурятия & 0,627 \\
\hline Краснодарский край & 0,914 \\
\hline Кировская область & 0,716 \\
\hline Приморский край & 0,815 \\
\hline
\end{tabular}

Источник: составлено автором

Следующий шаг - это проведение группировки регионов по индикаторам, характеризующим состояние инвестиционного климата, с целью выявления зависимости между состоянием инвестиционного климата и эффективностью инвестиционных налоговых льгот. Для ее составления необходимо определить количество групп и интервалы группировки. Предлагаем сформировать 4 группы с равными интервалами. После проведенных расчетов была составлена таблица, в которой отражено распределение регионов по группам (табл. 1).

Сформировав исходную базу данных, проведем дисперсионный анализ 
на предмет определения влияния состояния инвестиционного климата на эффективность налоговых льгот. Выдвигаем гипотезу $\mathrm{H}_{0}$ о том, что фактор незначим, то есть состояние инвестиционного климата не оказывает влияния на эффективность налоговых льгот. Альтернативная гипотеза $\mathrm{H}_{1}$, что фактор значим, то есть оказывает существенное влияние на результирующий признак. Задаем уровень значимости 0,05. Используя инструменты программы MS Excel, проводим дисперсионный анализ. Поскольку эмпирическое значение статистики критерия Фишера $(6,45988)$ больше критического значения $(3,2388)$, с вероятностью 0,95 гипотеза $\mathrm{H}_{1}$ принимается, то есть инвестиционный климат оказывает влияние на эффективность налоговых льгот.

Так как фактор значим, находим коэффициент детерминации по формуле (8):

$$
R^{2}=\frac{S S_{\text {факт }}}{S S_{\text {общ }}} \times 100 \%=\frac{0,5192}{0,9479} \times 100 \%=54,77 \%
$$

Коэффициент детерминации показывает, что уровни фактора объясняют вариацию результирующего показателя на 54,77\%, то есть состояние инвестиционного климата объясняет вариацию коэффициентов экономической эффективности инвестиционных налоговых льгот на 54,77\%, оставшиеся 45,23\% приходятся на другие факторы.

\section{Результаты исследования и их обсуждение}

Результаты проведенного дисперсионного анализа позволяют сделать вывод о целесообразности расчета индикаторов инвестиционного климата на этапе введения налоговых льгот. Научная новизна и практическая значимость предложенного инструментария состоит в том, что он делает анализ на этапе введения льгот более комплексным, ведь согласно сложившейся практике, регионы прогнозируют основные показатели эффективности только в том случае, если льготы предоставляются конкретному инвестиционному проекту. Однако важно понимать, что в условиях рыночной экономики налоговые льготы вводятся с целью привлечения инвесторов из других субъектов и стран, и поэтому рассматриваются в качестве меры, повышающей конкурентные преимущества региона перед другими субъектами. Соответственно, льготы, как правило, вводятся тогда, когда отсутствуют потенциальные проекты-бенефициары. Это означает, что прогноз эффективности льгот невозможен. Именно поэтому имеет смысл проводить сравнительный анализ и ориентироваться на другие регионы, в частности, на состояние инвестиционного климата, на их налоговую нагрузку на инвестиции, чтобы оценить, насколько создаваемый льготный режим действительно выгоден по сравнению с другими регионами.

Сформулированные выше тезисы считаем необходимым конкретизировать. Например, Республика Бурятия планирует ввести инвестиционные налоговые льготы для резидентов индустриального парка при условии, что пока реестр резидентов не пополнялся (прогноз эффективности невозможен). Планируемая льготная налоговая ставка составляет 12,5\%. При этом индустриальные парки созданы и в других регионах, где также действует преференциальный налоговый режим. В анализ были включены эти регионы (имеется информация в открытом доступе и функционируют индустриальные парки), хотя, на практике, безусловно, большую ценность имеет сравнение с соседними регионами. При этом во всех субъектах установлена одинаковая ставка, что затруд- 
няет анализ. В связи с чем в дополнение к индикаторам инвестиционного климата предлагается исчислять предельные эффективные налоговые ставки для новых инвестиций (далее METR). METR - это прогнозная налоговая ставка, ставка ex ante, которая представляет собой отношение налогового клина к реальной отдаче капитала до налогообложения $[17,18]$. Экономическая сущность предельной налоговой ставки, как и любой предельной величины, состоит в том, что она показывает то налоговое бремя, с которым столкнется инвестор при осуществлении дополнительных инвестиций.

Из потенциальных регионов-конкурентов Республика Бурятия имеет самую низкую предельную эффективную ставку, что является для нее конкурентным преимуществом (табл. 4). Однако для комплексного анализа необходимо учитывать индикаторы инвестиционного климата, которые представляют собой итоговую характеристику конкурентных позиций региона. Среди анализируемых регионов Республика Бурятия характеризуется наименее благоприятным инвестиционным климатом. Как видим, наименьший разрыв наблюдается с Кемеровской и Иркутской областями, исходя из чего следует заключить, что пониженную налоговую ставку можно расценивать в качестве фактора, компенсирующего более низкий инвестиционный климат. Одновременное сопоставление предельных ставок и индикаторов инвестиционного климата с оставшимися регионами позволяет сделать вывод, что планируемые к введению налоговые льготы имеют весьма ограниченный потенциал в повышении инвестиционной привлекательности территории.

Таблииа 4

Значения предельных эффективных ставок и индикаторов инвестиционного

климата

\begin{tabular}{|l|c|c|c|}
\hline \multicolumn{1}{|c|}{ Субъект РФ } & $\begin{array}{c}\text { Законодательно установленная } \\
\text { налоговая ставка }\end{array}$ & МЕTR & $\begin{array}{c}\text { Индикатор инвестици- } \\
\text { онного климата }\end{array}$ \\
\hline Кемеровская область & 13,5 & 7,82 & 0,631 \\
\hline Ставропольский край & 13,5 & 10,68 & 0,792 \\
\hline Иркутская область & 13,5 & 13,2 & 0,723 \\
\hline Республика Бурятия & 12,5 & 5,14 & 0,627 \\
\hline Ростовская область & 13,5 & 8,21 & 0,848 \\
\hline Липецкая область & 13,5 & 8,21 & 0,949 \\
\hline
\end{tabular}

Источник: составлено автором

Таким образом, в условиях рыночной экономики, где регионы выступают в роли квазикорпораций, конкурирующих за привлечение инвестиционных ресурсов, целесообразно на этапе введения налоговых льгот проводить сравнительный анализ состояния инвестиционного климата, поскольку как показало проведенное исследование, социально-экономическая и институциональная среда оказывает влияние на эффективность инвестиционных налоговых льгот.

\section{Список источников / References}

1. Макарова И.А. Функции налогов. Вестник Томского государственного универсиmema, 2007, №304, cc. 163-166. [Makarova I.A. Funkcii nalogov [Functions of taxes]. Vestnik Tomskogo gosudarstvennogo universiteta = Bulletin of Tomsk state university, 2007, no. 304, pp. 163-166.]

2. Горский И.В. О налоговом регулировании, налоговых льготах и функциях (историко-методологический аспект). Экономика. Налоги. Право, 2014, №3, сс. 17-22. [Gorskij I.V. O nalogovom regulirovanii, nalogovyh lgotah i funkciyah (istorikometodologicheskij aspekt) [On the tax regulation, tax incentives and functions (historical and methodological aspect)]. E`konomika. Nalogi. Pravo = Economics. Taxes. Law, 2014, 
no. 3, pp. 17-22.]

3. Johnson L., Toledano P., Strauss I. Background paper on investment incentives: the good, the bad and the ugly: assessing the costs, benefits and options for policy reform. Columbia University Academic Commons, 2013. Available at: http://ccsi.columbia.edu/files/2014/01/VCC_conference_paper_Draft_Nov_12.pdf (accessed 02.04.2018).

4. A Handbook for Tax Simplification. International Finance Corporation. Pennsylvania Avenue, N.W., Washington D.C., 2009. 242 p.

5. Постановление Правительства Омской области от 19 дек. 2007 г. № 173-П «Об оценке эффективности предоставленных и планируемых к предоставлению налоговых льгот» [Postanovlenie Pravitelstva Omskoj oblasti ot 19 dek. 2007 g. № 173 -p «Ob ocenke ehffektivnosti predostavlennyh i planiruemyh k predostavleniyu nalogovyh lgot» [Government decree of Omsk region of 19 December 2007 № 173-d "On assessment of efficiency of granted or projected to grant tax incentives"]. Available at: http://docs.cntd.ru/document/943025400 (accessed 05.01.2018).

6. Постановление Правительства Хабаровского края от 4 сент. 2012 г. № 312 -пр «Об утверждении порядка оценки эффективности налоговых льгот» [Postanovlenie Pravitelstva Habarovskogo kraya ot 4 sent. 2012 g. № 312-pr «Ob utverzhdenii poryadka ocenki ehffektivnosti nalogovyh lgot» [Government decree of Habarovsk region of 4 September 2012 № 312-d "On adoption of procedure for assessment of efficiency of tax incentives"]. Available at: http://docs.cntd.ru/document/995154378 (accessed 06.01.2018).

7. Постановление Правительства Новосибирской области от 22 июля 2013 г. № 318-п «О критериях эффективности налоговых льгот, установленных иным категориям налогоплательщиков» [Postanovlenie Pravitelstva Novosibirskoj oblasti ot 22 iyulya 2013 g. № 318-p «O kriteriyah ehffektivnosti nalogovyh lgot, ustanovlennyh inym kategoriyam nalogoplatelshchikov» [Government decree of Novosibirsk region of 22 July 2013 № 318-d “On efficiency criteria of tax incentives granted to particular taxpayers”]. Available at: http://novosibirsk.regnews.org/doc/jq/3n.htm (accessed_06.01.2018).

8. Постановление Правительства Амурской области от 7 февр. 2012 г. № 55 «Об оценке эффективности предоставления льгот по региональным налогам и установления пониженных ставок по налогу на прибыль организаций» [Postanovlenie Praviteltva Amurskoj oblasti ot 7 fevr. 2012 g. № 55 «Ob ocenke ehffektivnosti predostavleniya lgot po regionalnym nalogam i ustanovleniya ponizhennyh stavok po nalogu na pribyl organizacij» [Government decree of Amur region of 7 February 2012 № 55 “On assessment of efficiency of granted tax incentives of regional tax es and reduced rate of corporate income tax"]. Available at: http://docs.cntd.ru/document/961721254 (accessed 07.01.2018).

9. Литвинова В.В. Инвестиционная привлекательность и инвестиционный климат региона. Москва, Финансовый университет, 2013. 116 с. [Litvinova V.V. Investicionnaya privlekatelnost i investicionnyj klimat regiona [Investment attractiveness and investment climate of region]. Moscow, Financial University Publ., 2013. 116 p.]

10. Саати Т. Принятие решений. Метод анализа иерархий. Москва, Радио и связь, 1993. 278 c. [Saati T. Prinyatie reshenij. Metod analiza ierarhij [Decision-making. Analytical hierarchy process]. Moscow, Radio and Communication Publ., 1993. 278 p.]

11. Ногин В.Д. Упрощенный вариант метода анализа иерархий на основе нелинейной сверстки критериев. Журнал вычислительной математики и математической физики, 2004, №7, сс. 1259-1268. [Nogin V.D. Uproshchennyj variant metoda analiza ierarhij na osnove nelinejnoj sverstki kriteriev [The simplified version of method of analytical hierarchy process based on nonlinear convolution of criteria]. Zhurnal vy`chislitel ’noj matematiki $i$ matematicheskoj fiziki = Journal of Computational Mathematics and Mathematical Physics, 2004, no. 7, pp. 1259-1568.]

12. Гулин Д.А., Зубкова О.В. Использование сбалансированной системы показателей для оценки инвестиционных процессов в регионе. Вестник ЮУрГУ. Серия: Эконо- 
мика и менеджмент, 2013, №2, сc. 13-17. [Gulin D.A., Zubkova O.V. Ispolzovanie sbalansirovannoj sistemy pokazatelej dlya ocenki investicionnyh processov $\mathrm{v}$ regione [Use of balanced scorecard for the assessment of regional investment process]. Vestnik YuUrGU. Seriya: E`konomika i menedzhment = Bulletin of SUSU. Series "Economics and Management”, 2013, no. 2, pp. 13-17.]

13. Кочегарова Л.Г., Закиров Р.Ш. Дифференцированный подход к управлению региональными инвестиционными процессами. Вестник УрФУ. Серия экономика и управление, 2015, №6, сc. 917-934. [Kochegarova L.G., Zakirov R.SH. Differencirovannyj podhod k upravleniyu regionalnymi investicionnymi processami [The differentiated approach to management of regional investment processes]. Vestnik UrFU. Seriya e konomika i upravlenie = Bulletin of UFU. Series Economics and Management, 2015, no. 6, pp. 917-934.]

14. Ройзман И., Бондарева Т. Динамика инвестиционной привлекательности и инвестиционной конкурентоспособности российских регионов в среднесрочной перспективе. Инвестиции в России, 2008, №9, сс. 3-13. [Rojzman I., Bondareva T. Dinamika investicionnoj privlekatelnosti i investicionnoj konkurentosposobnosti rossijskih regionov $\mathrm{v}$ srednesrochnoj perspective [Dynamics of investment attractiveness and investment competitiveness of Russian regions in the medium term]. Investicii $v$ Rossii $=$ Investment in Russia, 2008, no. 9, pp. 3-13.]

15. Министерство экономического развития РФ. Прогноз долгосрочного социальноэкономического развития Российской Федерации на период до 2030 года [Ministerstvo ehkonomicheskogo razvitiya RF. Prognoz dolgosrochnogo socialnoehkonomicheskogo razvitiya Rossijskoj Federacii na period do 2030 goda [Ministry of economic development of the Russian Federation. Forecast of long-term socio-economic development of the Russian Federation for the period up to 2030]. Available at: http://economy.gov.ru/minec/activity/sections/macro/prognoz/doc20130325_06 (accessed 12.03.2018).

16. Регионы России. Социально-экономические показатели. 2017: стат. сб. Москва, Росстат, 2017. 1402 c. [Regiony Rossii. Socialno-ehkonomicheskie pokazateli. 2017: stat. sb. [Regions of Russia. Socio-economic indicators. 2017: stat. bulletin]. Moscow, Russtat Publ., 2017. 1402 p.]

17. Effective marginal tax rates on new investment methodology. Office of Tax Analysis U.S. Department of the Treasury Report. July 2014. Available at: https://www.treasury.gov/resource-center/tax-policy/tax-analysis/Documents/NewInvestment-Rates-Methodology.pdf (accessed 02.01.2018).

18. Карзанова И.В. Воздействие налогового режима на инвестиции в реальный сектор российской экономики: предельные эффективные налоговые ставки на инвестиции в материальные активы, человеческий капитал и НИОКР. М.: EERC, 2005. 56 с. [Karzanova I.V. Vozdejstvie nalogovogo rezhima na investicii v realnyj sektor rossijskoj ehkonomiki: predelnye ehffektivnye nalogovye stavki na investicii v materialnye aktivy, chelovecheskij kapital i NIOKR [The impact of tax regime on investment into the real sector of Russian economy: margin effective tax rate on investment in tangible assets, human capital, R\&D]. Moscow, EERC Publ., 2005. 56 p.]

Сведения об авторе / About author

Попова Евгения Михайловна, старший преподаватель кафедры мировой экономики, предпринимательства и гуманитарных дисциплин, Читинский институт (филиал) Байкальского государственного университета. 672000 Россия, г. Чита, ул. Анохина, 56. E-mail: p_e_m_2013@mail.ru Evgeniya M. Popova, Senior Lecturer of Department of World Economy, Entrepreneurship and Humanities. Chita Institute Baikal State University. 56, Anohina Street, Chita, 672000, Russian Federation. E-mail:p_e_m_2013@mail.ru 